\title{
Assessing Country's Readiness for adopting Transportation Public Private Partnerships: The Case of Pakistan
}

\author{
Shafiq Ahmed Soomro ${ }^{1}$, Mohsin Ali Soomro ${ }^{2}$ and Aftab Hameed Memon ${ }^{2}$ \\ ${ }^{\prime}$ (Director, National Highway Authority, Pakistan) \\ ${ }^{2}$ (Assistant Professor, Department of Civil Engineering, Quaid-e-Awam University of Engineering, Science and \\ Technology, Nawabshah, Pakistan )
}

\begin{abstract}
Public Private Partnerships (PPPs) are seen as the opportunity to circumvent the budgetary and technical constraints to develop public infrastructures. PPPs are representing a useful tool for developing nations to boost the economic development by means of inducing private sector in public infrastructure business. Nevertheless, developing and managing PPPs has never been an easy job. The history is full of failed and flawed PPPs, which have yielded heavy losses to the public. As a matter of fact, there are a number of factors that collectively define the perfect environment for a successful PPP. The United Nations Economic and Social Commission for Asia and the Pacific (ESCAP) has developed an instrument, in a form of a questionnaire, which is prescribed as a test to assess PPP readiness for any country. This paper has adopted the similar questionnaire to determine if the national economic and institutional conditions in Pakistan are sufficient to develop transportation PPPs that can deliver value to the public. The results yielded by the test have shown that Pakistan still lacks the satisfactory level of necessary factors, which are considered a precursor. Such, identification of this study will help policy makers in understanding the persisting issues pertaining to the development of transportation PPPs in Pakistan, and will help the private sector investors in better understanding of the local market.
\end{abstract}

Keywords -transportation; public private partnerships; readiness assessment; Pakistan

\section{Introduction}

Private sector involvement has always been a constituent of economic growth. With growth, comes the requirement of infrastructure. Or, with the availability of better infrastructure, comes along the economic growth. The participation of private entities in partnership with government agencies to build the infrastructure brings a win-win situation for both the public and the private sector [1]. The developed economies, and even the developing ones, have recognized the importance of the private sector's role in the economic and social development [2].

Public Private Partnership (PPP) is a tool that enables efficient partnership between a public sector organization and a private sector entity. A PPP may have many types; such as 'Build Operate Transfer (BOT)', 'Build Own Operate (BOO)', 'Design Built Finance \& Operate (DBFO)' etc.,[3]. All variants of PPPs actually depict the level of responsibility and risk sharing among public and private sector partners. The PPPs facilitate governmental agencies in building and managing public infrastructure by means of averting restrictions of limited resources, reducing the risks associated with project execution, refuting the problems of funds shortages; and creating a prospect business for private sector to invest in infrastructure market. Since the requirement of infrastructure is always there, and the budgetary allocationsfor development cannot do the justice, especially in the case of developing countries. Therefore, the PPPs are the greatest opportunity for executing public projects with the extended economy, efficiency and effectiveness.

Transportation is one the major infrastructure sector in which PPPs have shown remarkable achievements. However, it is a sad fact that despite a huge potential in the local market, the share of Pakistan in developingtransportation PPP market, in comparison with its neighboring countries is quite low. The World Bank's database of public participation in infrastructure [4] reflects the low investment standing. Such fact persists due to a reality that organizing PPPs is never been an easy job.

The recent PPP literature points to the importance of favorable PPP factors, especially, positive regulatory and public institutional framework [5]. However, the successful implementation of Transportation PPP requires far-more fundamentals. The fundamentals of PPP framework are refereeing to the availability of a variety of protocols in legal, political, social, institutional, and in policymaking domains, which must collectively recognize and regulate private business activities in public infrastructures. Therefore, without taking any of the above mentioned domains in considerations, any transportation PPP venture may not deliver the desired goals, and then may be rated a failure.

Previously many researchers have strived hard to evaluate and formulate factors that are necessary to make PPP projects a success. Among such efforts, the most cited and prominent findings are provided below; 
The Ref [6] has identified six critical success factors (CSFs) in winning BOT contracts: (1) entrepreneurship and leadership, (2) right project identification, (3) strength of the consortium, (4) technical solution advantage, (5) financial package differentiation, and (6) differentiation in guarantees. The approach of identification of potential success factors is then succeeded by the reference [7] by broadening the scope to other forms of PPPs. The reference [7] has presented five critical success factors (CSFs), with sets of sub success factors, for infrastructure development PPPs. The five CSFs are (1) favorable investment environment, (2) economic viability (3) reliable concessionaire with strong technical strength (4) sound financial package and (5) appropriate risk allocation via reliable contractual arrangements. The reference [9] then has evaluated CSFs for private finance initiative (PFI), a variant of PPP, projects in the United Kingdom. Besides the CSFs approach, massive research has been conducted on other PPP issues. For example, [8] has worked out methods and criteria for selection of concessionaire, The reference [10] has presented a knowledge based approach for PPP stakeholder management, and the reference [11] has applied alliance principals for better outputs of PPP projects.

All such factors, collectively determines a mature environment to develop a PPP or a transportation PPP that could yield benefits for both, the public and the private sector. Similarly, this study attempts to identify the readiness of Pakistani environment to embrace transportation PPPs. For this purpose, a questionnaire developed by the United Nations Economic and Social Commission for Asia and the Pacific (UNESCAP) [12] is used with slight modifications in its measuring scales. This paper intends to capture PPP readiness to develop transportation PPPs in Pakistan. The following paragraphs further elaborate on the methodology adopted.

\section{Research Methodology}

The research methodology is divided in three sequential phases, i.e., as follow;

1. Design of transportation PPPP readiness assessment instrument

2. Selection of participants

3. Expert group consultation

4. Statistical analysis and interpretation of results

\section{Design of transportation PPPP readiness assessment instrument}

The instrument to assess a country's readiness to embrace transportation PPP regime is borrowed from the Transport and Tourism Division department of The United Nations Economic and Social Commission for Asia and the Pacific (ESCAP) [12]. The ESCAP's [12] questionnaire instrument, titled 'Public Private Partnership Readiness - Self Assessment Form', contains the most rigors among all other available instruments or researches done previously.

The questionnaire is subdivided in two main parts. The first part tends to focus 'indicators on general business background', which is assessing the availability and status of fundamental factors that assures positive gestures for private investments. The indicators on general business backgrounds are then assessed under four subheads, i.e., (i) macroeconomic environment, (ii) business climate, (iii) financial environment and, (iv) legal and governance Environment. The second part of the questionnaire is designed to solicit information on factors pertaining specifically to the establishment of PPPs. The indicators assessing PPP environment are, (i) legal and regulatory provision for PPP, (ii) PPP policy framework, (iii) PPP capacity, (iv) PPP process: project selection and contracting, (v) PPP process: post-selection, and (vi) social dimension of PPP policy.

\section{Selection of participants}

A total of 11 professionals specialized in the field of transportation PPPs have agreed to be a part of this study. The participants included director and deputy directors of the PPP cell of the National Highway Authority, three deputy directors of different department (working on PPP projects) of a public sector highway authority, a CEO and a financial analyst from two private sector companies and two academic researchers. Both public and private sector representatives depict a high profile in their respective organizations in developing, managing, regulating, researching and providing training sessions on managing transportation PPPs in Pakistan. Therefore, the authors are assured that conclusions made based on the analysis are enough to depict the right picture of transportation PPPs in Pakistan. Table 1 shows the profiles of transportation PPP experts participated in this study.

Table 1 Profile of participants of the expert group

\begin{tabular}{|c|c|c|c|}
\hline $\begin{array}{c}\text { Nature of } \\
\text { Organization }\end{array}$ & QTY & Designation & $\begin{array}{c}\text { Experiment with PPP } \\
\text { (in Years) }\end{array}$ \\
\hline Public Sector Partners & 2 & Director and Deputy Director (PPP Cell) & 9 \\
\hline Public Sector Partners & 4 & $\begin{array}{c}\text { Deputy Director (Engineering); Deputy Director } \\
\text { (Construction); Deputy Director (Revenue) }\end{array}$ & 5 \\
\hline
\end{tabular}


Assessing Country's Readiness for adopting Transportation Public Private Partnerships: The Case ..

\begin{tabular}{|c|c|l|c|}
\hline $\begin{array}{c}\text { Nature of } \\
\text { Organization }\end{array}$ & QTY & \multicolumn{1}{|c|}{ Designation } & $\begin{array}{c}\text { Experiment with PPP } \\
\text { (in Years) }\end{array}$ \\
\hline Private Sector Partners & 3 & CEO and Financial Analyst & 10 \\
\hline Academic Researchers & 2 & Assistant Professor & 6 \\
\hline
\end{tabular}

Table 2 the scores attained by the transportation PPP readiness assessment test

\begin{tabular}{|c|c|c|c|}
\hline \multicolumn{2}{|c|}{ Indicators on general background } & Mean & St. Dev \\
\hline \multicolumn{4}{|c|}{ Macroeconomic Environment } \\
\hline 1 & Satisfactory balance of payments position & 3.27 & 0.86 \\
\hline 2 & Low unemployment rate & 3.09 & 0.51 \\
\hline 3 & Stable and reasonable real interest rates & 3.09 & 0.90 \\
\hline 4 & Acceptable debt service ratio & 3.09 & 1.08 \\
\hline 5 & Satisfactory growth rates in key sectors & 3.00 & 0.74 \\
\hline 6 & Business confidence high & 2.82 & 1.03 \\
\hline 7 & Stable exchange rate & 2.82 & 0.83 \\
\hline 8 & GDP growing at an acceptable rate & 2.73 & 0.86 \\
\hline 9 & Fiscal budget balance & 2.73 & 1.05 \\
\hline 10 & Price stability & 2.64 & 0.88 \\
\hline \multicolumn{4}{|c|}{ Business Climate } \\
\hline 11 & Education produces sufficient quantity of sufficiently skilled graduates & 3.36 & 0.77 \\
\hline 12 & Few restrictions on repatriation of profits & 3.18 & 0.57 \\
\hline 13 & Convertibility of foreign exchange & 3.18 & 0.83 \\
\hline 14 & Rational, equitable and predictable taxation policies & 2.91 & 0.90 \\
\hline 15 & Reasonable tax levels for corporations & 2.91 & 0.51 \\
\hline 16 & Possible to register and get permission to start up a new business quickly and easily & 2.91 & 1.00 \\
\hline 17 & Physical infrastructure adequate & 2.91 & 0.67 \\
\hline 18 & Fields of specialized education appropriate for country needs & 2.82 & 0.57 \\
\hline 19 & Precedents shows government to be responsive to PPP business concerns & 2.73 & 0.62 \\
\hline 20 & Commitment to maintain policy continuity & 2.64 & 0.77 \\
\hline \multicolumn{4}{|c|}{ Financial Environment } \\
\hline 21 & Effective financial regulatory regime in place & 3.82 & 1.03 \\
\hline 22 & Developed banking system services corporate needs & 3.73 & 0.62 \\
\hline 23 & Developed equity markets & 3.45 & 0.78 \\
\hline 24 & Credit rating agency(s) exist and offer ratings on individual businesses & 3.27 & 0.96 \\
\hline 25 & Developed pension and insurance market & 3.18 & 0.72 \\
\hline 26 & Clear and effective provision for bankruptcy and limited shareholder liability & 3.18 & 0.94 \\
\hline 27 & Financial sector experienced in assessing long-term lending decisions & 3.18 & 1.19 \\
\hline 28 & Bond market exists and is open to private participation & 3.00 & 0.74 \\
\hline \multicolumn{4}{|c|}{ Legal and Governance Environment } \\
\hline 29 & Environmental laws are clear and transparent and are all available from a single source & 3.45 & 0.89 \\
\hline 30 & Press is free, formally and in practice & 3.27 & 0.96 \\
\hline 31 & Government procurement is fair and transparent in practice & 2.91 & 1.31 \\
\hline 32 & Property rights effectively enforced, and compensation for expropriation is fair & 2.82 & 1.11 \\
\hline 33 & Community and stakeholder participation in government policy making & 2.82 & 1.03 \\
\hline 34 & Labor legislation effective in protecting workers' wages and safety & 2.82 & 1.11 \\
\hline 35 & Judiciary demonstrates competence, independence and efficiency & 2.73 & 1.05 \\
\hline 36 & Environmental protection adequate & 2.73 & 1.14 \\
\hline 37 & Effective protection for intellectual property, including business models & 2.64 & 0.98 \\
\hline 38 & Government addressing problems of corrupt corporate practices & 2.64 & 1.07 \\
\hline 39 & Effective political commitment to eradicate public sector corruption & 2.55 & 1.23 \\
\hline 40 & Political commitment to public and private financial transparency & 2.45 & 0.99 \\
\hline \multicolumn{4}{|c|}{ Indicators focusing on PPP issues } \\
\hline \multicolumn{4}{|c|}{ Legal and Regulatory Provision for PPP } \\
\hline 41 & Authority and procedures are clear for acquiring rights of way & 3.73 & 0.96 \\
\hline 42 & Legal basis for private sector participation in PPP is clearly defined & 3.45 & 0.89 \\
\hline 43 & Limited restriction on participation of foreign investors in PPP projects & 3.45 & 0.99 \\
\hline 44 & Regulatory authority is clear for all PPP types expected & 3.36 & 1.07 \\
\hline 45 & Powers and resources are adequate to regulate PPP & 3.36 & 0.98 \\
\hline 46 & Accounts of PPP projects available to regulators and subject to effective query & 3.36 & 1.07 \\
\hline 47 & Price regulation sufficiently flexible to adjust to major cost changes & 3.18 & 0.83 \\
\hline 48 & Judiciary understands and accepts PPP policy framework & 3.00 & 1.21 \\
\hline 49 & Price and quality of PPP monopolies regulated to protect consumers and others & 3.00 & 1.13 \\
\hline 50 & Regulators demonstrate competence, independence and efficiency & 2.91 & 1.16 \\
\hline \multicolumn{4}{|c|}{ PPP Policy Framework } \\
\hline 51 & PPP policy has clearly allocated authority and responsibility within the parts of government & 3.73 & 1.14 \\
\hline 52 & Distinct process for unsolicited PPP proposals in policy framework & 3.73 & 1.05 \\
\hline 53 & Projects are integrated with the national and local planning process & 3.73 & 1.05 \\
\hline 54 & Project support requirements are integrated with government budget process & 3.73 & 1.05 \\
\hline 55 & Policy framework generates commercially viable project proposals & 3.64 & 1.15 \\
\hline 56 & Criteria for project support by government are clearly defined & 3.64 & 1.30 \\
\hline
\end{tabular}




\begin{tabular}{|c|c|c|c|}
\hline 57 & Effective process defined for proposing, identifying and structuring projects & 3.55 & 1.30 \\
\hline 58 & PPP policy undergoes evaluation and revision in response to experience & 3.45 & 1.30 \\
\hline 59 & Private participation in PPP projects has clear basis in policy, with broad government support & 3.18 & 1.11 \\
\hline 60 & Sectoral competition and regulatory regime chosen to limit market power & 3.18 & 1.11 \\
\hline 61 & Stakeholders can participate in project planning and implementation & 3.09 & 1.24 \\
\hline \multicolumn{4}{|c|}{ PPP Capacity } \\
\hline 62 & PPP process has sufficient political support, due to positive record or political "champion" & 3.55 & 1.16 \\
\hline 63 & Defined government mechanisms in place to coordinate PPP needs & 3.27 & 0.96 \\
\hline 64 & Staff can assess outside work, including feasibility studies and risk mitigation strategies & 3.18 & 0.72 \\
\hline 65 & PPP documentation/best practices available in public domain & 3.18 & 1.34 \\
\hline 66 & Technical capacity sufficient to ensure construction and service standards & 3.09 & 0.79 \\
\hline 67 & Provision for assisting line agencies and local government in undertaking PPP projects & 2.91 & 0.90 \\
\hline 68 & Staff capable of routine operations in PPP project development & 2.82 & 1.11 \\
\hline 69 & Staff of relevant government agencies have resources/information for managing PPP process & 2.64 & 0.88 \\
\hline 70 & Staff aware of legal, financial and basic technical issues in PPP projects & 2.64 & 0.88 \\
\hline 71 & Adequate resources/facilities and expertise to train in PPP & 2.45 & 0.66 \\
\hline \multicolumn{4}{|c|}{ PPP Process: Project selection and contracting } \\
\hline 72 & Bidders given proper information, including requirements for submitting proposals & 4.00 & 1.13 \\
\hline 73 & Verification of business information used in sponsor selection & 3.73 & 1.35 \\
\hline 74 & Objective criteria for project sponsor selection are known and applied & 3.73 & 0.86 \\
\hline 75 & Transparent procedures specified for all stages of the PPP process & 3.55 & 1.08 \\
\hline 76 & Project feasibility studies undertaken for larger proposals & 3.55 & 1.30 \\
\hline 77 & Environmental and social impact assessment required & 3.45 & 1.23 \\
\hline 78 & Customer safety assessment fully incorporated & 3.36 & 1.37 \\
\hline 79 & Conflict of interest results in exclusion from contracting & 3.27 & 1.21 \\
\hline 80 & Competitive tendering process is transparent in practice & 3.27 & 1.29 \\
\hline 81 & Predictable staging of project identification, selection and contracting & 2.82 & 0.94 \\
\hline \multicolumn{4}{|c|}{ PPP Process: Post-Selection } \\
\hline 82 & Defined performance requirements available prior to bidding & 4.00 & 0.74 \\
\hline 83 & Penalties enforced for failure to meet contractual obligations & 3.64 & 1.23 \\
\hline 84 & Technical regulation is appropriate to project requirements & 3.64 & 0.98 \\
\hline 85 & Contracts for PPP are irrevocable except through due process & 3.45 & 1.08 \\
\hline 86 & Conflict resolution process clear, including alternatives to judicial resolution & 3.45 & 0.99 \\
\hline 87 & Rulings by technical and economic regulators can be appealed & 3.45 & 0.99 \\
\hline 88 & Performance monitoring effective and transparent & 3.27 & 1.14 \\
\hline 89 & Arrangements for risk sharing are sensible and manageable & 3.18 & 1.34 \\
\hline 90 & International arbitration recognized and effective for dispute resolution & 2.91 & 1.08 \\
\hline \multicolumn{4}{|c|}{ Social Dimension of PPP Policy } \\
\hline 91 & Resettlement and rehabilitation provided for communities disrupted by PPP projects & 3.18 & 1.27 \\
\hline 92 & Planning system addresses the needs of the poor and marginalized & 3.09 & 0.90 \\
\hline 93 & Pricing policies reflect the needs of the poor in basic services & 3.00 & 1.04 \\
\hline 94 & Funds available for projects with added social welfare purpose & 2.91 & 0.79 \\
\hline 95 & Mechanism for undertaking community-based infrastructure projects using PPP & 2.91 & 0.90 \\
\hline 96 & Community instruments (such as cooperatives) for equity participation in PPP available & 2.64 & 0.77 \\
\hline 97 & Civil society views PPPs as viable means of providing infrastructure and basic services & 2.36 & 1.07 \\
\hline 98 & Program to educate the public concerning the need for user-pays principle & 2.09 & 0.51 \\
\hline
\end{tabular}

Table 3Summarized results of transportation PPP readiness assessment

\begin{tabular}{|l|c|c|c|}
\hline Indicators on general background & Total score & Mean score & $\%$ gained score \\
\hline Macroeconomic Environment & 45 & 29.27 & $65.05 \%$ \\
\hline Business Climate & 50 & 29.55 & $59.09 \%$ \\
\hline Financial Environment & 40 & 26.82 & $67.05 \%$ \\
\hline Legal and Governance Environment & 60 & 33.82 & $56.36 \%$ \\
\hline Indicators focusing on PPP issues & & & \\
\hline Legal and Regulatory Provision for PPP & 50 & 32.82 & $65.64 \%$ \\
\hline PPP Policy Framework & 55 & 38.64 & $70.25 \%$ \\
\hline PPP Capacity & 50 & 29.73 & $59.45 \%$ \\
\hline PPP Process: Project selection and contracting & 50 & 34.73 & $69.45 \%$ \\
\hline PPP Process: Post-Selection & 45 & 31.00 & $68.89 \%$ \\
\hline Social Dimension of PPP Policy & 40 & 22.18 & $55.45 \%$ \\
\hline$\quad$ Total & $\mathbf{4 8 5}$ & $\mathbf{3 0 8 . 5 5}$ & $\mathbf{6 3 . 6 2 \%}$ \\
\hline
\end{tabular}

\section{Expert Group Consultation}

The 11 personnel having PPP experience agreed to be a part of this study comprises the expert group. An 'expert group' is a cluster of personnel having certain attributes of expertise [13] in a particular field that is being investigated. The selection of experts is explained in the previous section. The expert group is consulted in two consecutive phases. In a first stage, experts are asked to elaborate the general behavior of PPP climate in Pakistan, which is then followed by a structured interview. In the second stage, the experts are presented with 
the questionnaire, and are asked to rate its importance on a 5 point Likert scale. The collected responses are the statistically analyzed.

\section{Statistical Analysis}

Basic statistical tests conducted are included frequency analysis, the central tendency of responses (i.e., mean and median and standard deviation). In addition, the Cronbach Alpha test is also conducted to assess if the designed scale is able to measure the construct. Cronbach's alpha is used to determine if the questionnaire variables are measuring the targeted domain $[14 ; 15 ; 16]$. By default, the Cronbach alpha test values range between 0 and 1 . If the measured scores demonstrate good internal correlations among the items or construct being measured, the value of Cronbach's alpha test must exceed 0.7. The Software Package for Social Scientists (SPSS) [20] has been used to perform Cronbach's alpha test. The Cronbach alpha's results for the responses collected on the questionnaire is found as 0.991 , which reflects stability and higher consistency.

The mean score ranking is performed to reflect the collected responses in each category. Furthermore, ESCAP [12] has defined a rule for calculating the readiness assessment questionnaire responses, and the same method is then applied in this study. The method defined by the ESCAP [12] is simple, as it takes the average of all responses and then calculates the total score under each subhead and then totals it to reflect the readiness assessment in terms of percentage. Table 2 shows the scores attained by each factor and the respective subhead in the readiness assessment test. The summarized scores are then illustrated in the Table 3 , to demonstrate the country's readiness to embrace PPPs in the transportation sector. The readiness assessment conducted by this study has demonstrated $63.62 \%$ readiness, which shows that our economy is still in primitive stages.

\section{Discussions on questionnaire survey results}

The transportation PPP readiness assessment of Pakistan consists of two main parts; i.e., the indicators for general business background and the indicators focusing PPP issues. Indicators on general business backgrounds have attempted to evaluate the general behavior of business climate, especially financial and legal aspects. While, the indicators on PPP have attempted to identify capacity and provisions of facilitating private sector partners in general or specific area of public service and infrastructure delivery. As this study has focused transportation sector, therefore the results are explicitly demonstrating the readiness to develop transportation PPPs. Discussion on both categories is provided in following paragraphs.

\section{Indicators on General Background}

Among subheads in this part, the 'financial environment' has gained the highest score, i.e., 67.05. The financial environment pertains to the banking system, pension \& insurance markets, bond market, equity market, effective financial regulatory regime, bankruptcy \& limited shareholder liability, credit rating agencies, experienced financial sector, etc. The relative high scores by the participants of the expert group have shown confidence on the current financial environment.

The statistics for the 'macroeconomic environment' and the 'business climate in Pakistan' have scored quite near to each other. However, the percentage gained scores of around $60 \%$, for both subheadings, are not sufficient enough to attract foreign investors.

Figure 1 contains a line chart depicting private investments in Pakistan [4] in various sectors since 1989. Among all sectors, the share of transport is at the lowest. The private investment trend shown by the figure 1 clearly confirms the notion illustrated by the readiness test that still transport sector in Pakistan need to be enhanced a lot.

The subhead 'Legal \& governance environment' has marked the lowest scores in this category, which shows the need of huge improvement to attract private capital. The reference [17] has highlighted the economic consequences of judicial actions. The reference [17] has provided examples, based on previous cases highlighting PPP transections, on the impedes associated with the judiciary system, which has quoted a conclusion as "After all of the approvals are obtained, there is a fear that the court of law may take Suo-motto cognizance of the transaction and may issue the stay order. Consequently, a lengthy and time consuming proceedings may occur to decide the case. Alternatively, some other party not pleased with the outcome of the executive decision, given by the court of law, may file a petition that is again admitted by the courts". Such kinds of actions may be right in some contexts, but the cost of the economy associated with their actions must also be addressed. 


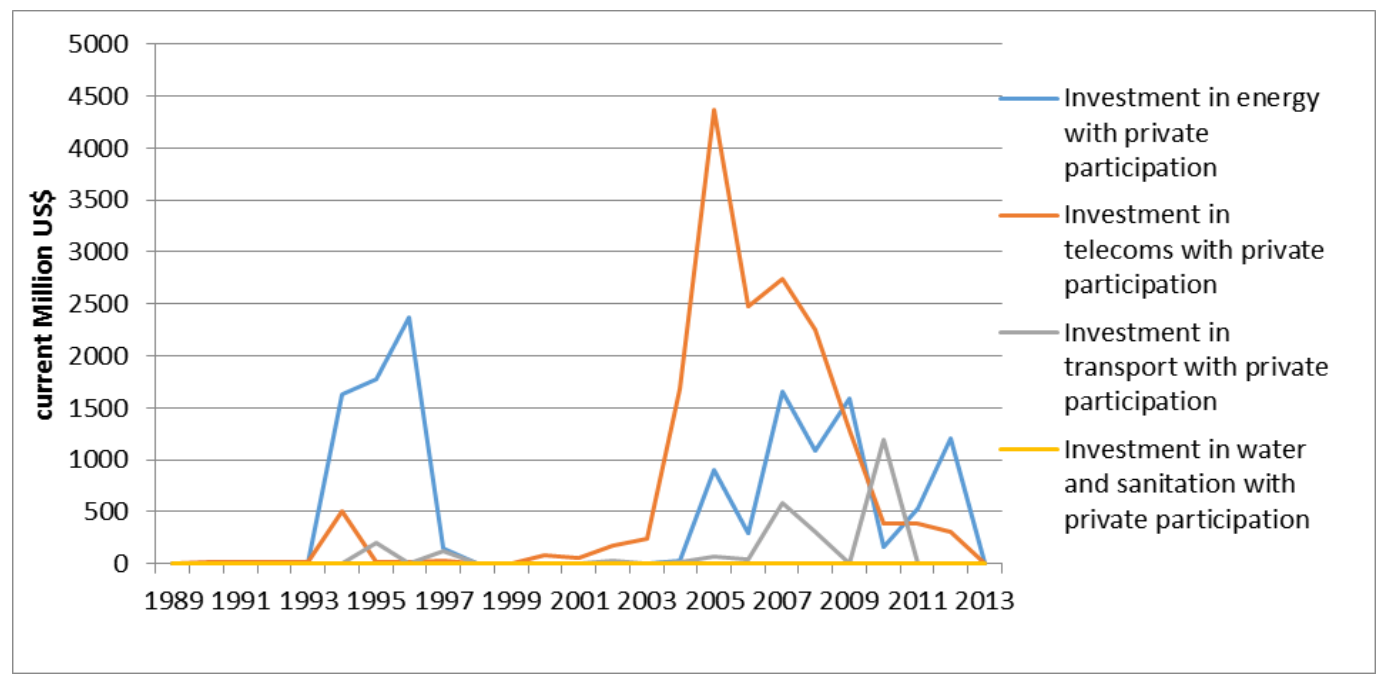

Figure 1 Private investments in Pakistan in various sectors since 1989.

The subhead 'Legal \& governance environment' has marked the lowest scores in this category, which shows the need of huge improvement to attract private capital. The reference [17] has highlighted the economic consequences of judicial actions. The reference [17] has provided examples, based on previous cases highlighting PPP transections, on the impedes associated with the judiciary system, which has quoted a conclusion as "After all of the approvals are obtained, there is a fear that the court of law may take Suo-motto cognizance of the transaction and may issue the stay order. Consequently, a lengthy and time consuming proceedings may occur to decide the case. Alternatively, some other party not pleased with the outcome of the executive decision, given by the court of law, may file a petition that is again admitted by the courts". Such kinds of actions may be right in some contexts, but the cost of the economy associated with their actions must also be addressed.

\section{Indicators Focusing on PPP Issues}

This part is divided in six subheads, i.e., systematically inspecting every fundamental aspect of developing and operating transportation PPPs. The total readiness indicator shows Pakistan's readiness at $63.62 \%$, however, if we look at the independent standing of indicators focusing PPP issues only, which is a bit higher at $65.2 \%$. Nevertheless, this score isindicating a huge room of improvement in almost every aspect of PPPs. Among all sub-categories, the highest scores of $70.25 \%$ are found for PPP policy framework and lowest scores $55.45 \%$ for the social dimension of PPP policy.

The expert group consultation, while informally interacting, has revealed a fact that policy on the PPP framework is quite mature, and especially forthe road sector it is quite clear. Similar is the reason that most of the transportation PPPs are in the road sector. Nevertheless, other transportation infrastructure sectors such as railway has started following the road sector and has embarked on very fist PPPs [18]. However, the recent improvement in Bus Rapid Transport Systems (BRTS) has been seen. The examples are Metro Bus in the cities of Lahore and Islamabad. Nevertheless, the BRTS is still limited only to the province of Punjab. Few attempts of developing policy framework for local PPPs in taxi services have been made by the government in the province of Sindh, but still no successful outcome is witnessed.

The 'PPP process' has attained the second rank, with relative scores of $69.5 \%$. Nevertheless, the situation of PPP process in terms of selecting and contracting lapses a lot from minimum requirement in many infrastructure sectors. For example, Capital Development Authority (CDA) is one of the prominent public sector institutions responsible for developing the capital territory. The CDA has no provision at all for facilitating any kind of PPP, a fact that is revealed by a participant of the expert group. However, the National Highway Authority of Pakistan, which is operating and regulating the largest segments of the country's highway infrastructure has established PPP cell, which is responsible for timely and efficiently processing the PPP proposal and the consequent procurement process. Nevertheless, an interview with the expert group participant has identified that despite the availability of proper framework, PPP procurements are taking a long time to realize. Upon enquiring about an approximate time, a rough estimate tells, that it takes at least 1 to 2 years from calling bids to finalize the selection private sector partner.

In order to speedup PPP process and to bring PPP policy and its associated advantages on grassroots level, provincial PPP units have been established in Pakistan. Such units have shown quite improvements in 
attracting private investors, and also have played an important role in bringing social and institutional understandings about PPPs and its advantages. The PPP units also have played a role in managing post concessionaire selection process, which includes finalizing the financial closure and deciding upon final allocation of the risk.

The expert group has identified a fact that, in the local scenario, the public sector has always wanted to transfer maximum risks to private sector partners, than to practice the fundamental law of the risk allocation, which emphasizes on allocation of a risk to the party able to mitigate it at the lowest cost. The expert group has also disclosed a fact that public sector institutions only wishes to retain legal and political risk.

The current 'legal and regulatory system' as an indicator on the PPP has scored 65.6\%, which marks the need of improvement in the respective sector. This study has identified interesting facts on local legal and PPP regulating system. Following paragraph has summarized the findings on PPP associated legal system.

Pakistan's legal system offers complex structures, which is due to the fact that the national federation is organized in multiple layers, i.e., ministries, the divisions, statutory bodies, etc. Among many of these, no hardline authority distinction is prescribed. Many of these layers depend upon each other in-terms of running their governmental business. Within such kind of legal framework, there are many restraints within the statutory framework to facilitate laws on the PPP. Nevertheless, some statuary bodies such as the National Highway Authority (NHA) are given limited power to develop legal aspects of PPP, up to some extent.

The lack of effective arbitration system adds further to the uncertainty circling transportation PPPs. Pakistan has the oldest arbitration law (1940) among all South Asian Association for Regional Cooperation (SARC) countries [19]. Therefore, to facilitate a PPP contract, there is a dire need to develop new effective laws for an effective resolution system. All other common wealth countries have amended and improved their arbitration laws, but Pakistan is still dealing with the 1940's law of arbitration, in which parties still have to approach the court after the resolution of dispute through arbitration to make it a legal binding. The expert group consultation has revealed that foreign investors are sensitive to the existing arbitration system, and, therefore, have been seeking guarantees from international mediators, such as the World Bank etc., to get PPP conflicts matters resolved in any other foreign arbitrator's office.

The indicators on social dimension of PPP policy have scored the least, i.e., 55.4\%. It is quite true that the current PPP system doesn't take notion of social welfare; or if it is considered, usually it is at its least. The expert group highlighted the strong need of community mobilization while developing transportation PPPs, especially when PPPs are meant to be developed on the only route corridors between two destinations.

\section{Conclusions}

This paper has attempted to assess Pakistan's readiness to embrace PPP culture to develop new and manage, both new and existing, transportation infrastructures. For the purpose, an expert group consultation is used to gather information on general business and PPP environment. The expert group is then asked to rate a series of factors prescribed by the UNESCAP [12], which collective can reflect a country's readiness to start PPP programs. The collected responses are then analyzed to comprehend the status of factors necessary to build successful PPPs. The PPP readiness assessment has reflected the country's readiness assessment at $63.62 \%$. If looking independent score of two main parts, then it is reflected that indicators on PPP issues have the readiness factor of $65 \%$. Among sub-categories, the highest readiness scores of $70.25 \%$ and $69.45 \%$ were found for PPP policy framework and for PPP process of selecting and contracting respectively. Nevertheless, the low score of legal framework and the social dimension has reflected the strong need of improvement. Based on the total scores, it is concluded that Pakistan is still in primitive stages to be a PPP favorite for both local and foreign investors.

\section{References}

[1]. Zhang X. Win-win concession period determination methodology. Journal of Construction Engineering and Management. 2009 May 15;135(6):550-8

[2]. Idris A, Kura SM, Bashir MU. Public private partnership in Nigeria and improvement in service delivery: An appraisal. Journal of Humanities and Social Sciences. 2013;10(3):63-71.

[3]. Zhang X. Critical success factors for public-private partnerships in infrastructure development. Journal of construction engineering and management. $2005 \mathrm{Jan} ; 131(1): 3-14$.

[4]. The World Bank. 2014. Private participation in infrastructure database. Accessed December 01, 2014.

[5]. Unit EI. Evaluating the environment for public-private partnerships in Asia-Pacific. The Economist. 2011.

[6]. Tiong, R. L. K. CSFs in competitive tendering and negotiation model for BOT projects, Journal of Construction Engineering and Management, 1996, Vol 122(3), pages: 205-211.

[7]. Zhang, X. Q. Critical Success Factors for Public-Private Partnerships in Infrastructure Development, Journal of Construction Engineering and Management, 2005, Vol 131(1), pages: 3-14.

[8]. Zhang, X. Q. Concessionaire selection: methods and criteria, Journal of Construction Engineering and Management, 2004, Vol 130 (2), pages: 235-244.

[9]. Li, B., Akintoye, A., Edwards, P. J., and Hardcastle, C. Critical success factors for PPP/PFI projects in the UK construction industry. Construction Management \& Economic, 2005, Vol 23(5), pages: 459-471. 
[10]. El-Gohary, Nora M., Osman, H., and Tamer, E. D. Stakeholder management for public private partnerships, International Journal of Project Management, 2006, Vol 24 (7), pages: 595-604.

[11]. Clifton, C., Duffield, C. F. Improved PFI/PPP service outcomes through the integration of Alliance principles", International Journal of Project Management, 2006, Vol 24 (7), pages: 573-586.

[12]. UNESCAP (2005) PPP Readiness Self-Assessment.<http://www.unescap.org/sites/default/files/ESCAP\%20PPP 20 Readiness $\% 20$ Tool.pdf > accessed Jan 10, 2014

[13]. Harman, A.J. and Press, S.J. Collecting and analyzing expert group judgment data. 1975.

[14]. Bowling, A. (1997). Research Methods in Health. Open University Press, Buckingham.

[15]. Bryman, A., and Cramer, D. (1997). Quantitative Data Analysis with SPSS for Windows. Routledge, London

[16]. Jack B, Clarke AM. The purpose and use of questionnaires in research. Professional nurse (London, England). 1998 Dec;14(3):176.

[17]. Husain, I. Economic Consequences of Judicial Actions. http://ishrathusain.iba.edu.pk/economic_consequences_ of_judicial_actions.html. Accessed June 01, 2016.

[18]. Railway Gazzet. Pakistan Railway signs night coach express PPP agreement. http://www.railwaygazette.com/news/passenger/ single-view/view/pakistan-railways-signs-night-coach-express-ppp-agreement.html. Accessed June 01, 2016

[19]. The arbitration law. www.wipo.int/edocs/lexdocs/laws/en/pk/pk066en.pdf, 1940, Accessed June 01, 2016 